\title{
The Design of a Hybrid Cultural Model for Arabic Gamified Systems
}

\begin{abstract}
The growing popularity of gamification in the global environment increases the importance of balancing factors that affect user engagement, satisfaction and acceptability in different cultures. While the main motivation behind gamifying software systems is to improve user engagement, an adverse effect might happen if the design and functionality did not consider users' cultural requirements. This paper presents a hybrid cultural design model for localising Arabic systems that takes into consideration the visual elements of user interfaces as well as the functionality and cultural factors of Arabic countries. We start by introducing design guidelines for localising Arabic systems and then evaluate the designed localisation criteria by conducting questionnaires and interviews. We base our studies on the factors that could affect the productivity levels of software engineers who use gamified software project management tools in their workplace. 63 software engineers participated in a mood board based questionnaire composed by different visual elements, rewards and achievements. To validate our findings, seven experts were interviewed. Those were software developers and designers. Based on our results, we propose a hybrid cultural design model, composed of personalised elements, localised elements and non-localised elements. This paper also proposes the first comprehensive model for localising Arabic gamified systems.
\end{abstract}

Keywords: Gamification, Game Element, Localisation, Culture, Motivation, Arabic.

\section{Highlights}

- A hybrid design model for the localisation of Gamified Systems in Arabic cultures.

- Arab systems could integrate universal, localised and personalised elements.

- Arab users would prefer to receive monetary rewards instead of social rewards.

- Arab users showed preference towards colouring features and badge design.

- The design model utilises visual elements and game design principles. 


\section{The Design of a Hybrid Cultural Model for Arabic Gamified Systems}

\section{Introduction}

Digital innovation and the Internet allowed people from different geographical locations to access and share different types of contents, shaped by cultural groups and identities. In this scenario, culture can have many effects on people's responses and preferences to communications and interactive systems. The use of properties of a specific culture in a webbased system that is targeting another cultural group might lead to losing business opportunities, which is resulted from users' confusion and frustration (Luna, Peracchio, \& de Juan, 2002). The results of the study presented in (Evers \& Day, 1997) show that users' acceptance of interfaces can be correlated with their cultural values and therefore variations in their satisfaction criteria might exist depending on the properties of the cultures that they belong to. For example, the satisfaction of a system's interface design of Chinese people is linked to its usefulness while Indonesian users give the ease of use a high priority for accepting a system (Khaslavsky, 1998). This finding can be correlated with Hofstede's value of uncertainty avoidance index in that, the Indonesian culture has higher value than the Chinese culture (Evers \& Day, 1997). Therefore, the consideration of culture in the design process of systems should not be overlooked. Innovation and sustainable development are enhanced by the valorisation of local and cultural values (UNESCO, 2013). This means that the consideration of culture is one of the main actors in innovation in different countries. Furthermore, the customization of software products according to specific cultures is continuously gaining more attention by user interface designers. However, there is a lack of studies considering the requirements for Middle Eastern cultures. For this reason, the localisation of software applications for Arabic cultures should be explored and emphasized in global markets contexts, considering cultural requirements and specific features.

In the scenario of interactive systems, it is possible to identify a shift towards design processes that could boost motivation, like gamification or the application of game mechanics into non-game settings (Deterding, Sicart, Nacke, O’Hara, \& Dixon, 2011). Considering software engineering, gamification could be applied into agile systems, particularly through the addition of experience points and scores (Zichermann \& Cunningham, 2011). In addition, other elements are part of gamification techniques, such as badges and leaderboards, providing a positive feedback to the user (Schrape, 2014). This means that there is a combination of elements that could be used in order to provide incentives and motivational outcomes for the users. However, this may vary according to individuals' backgrounds, their cultural beliefs and preconceived perceptions. Moreover, it is possible that culture could be a strong determinant of positive behaviour change and preferences inside a gamified system. Most of cross-cultural research has been focused on Western-based research (Wagner, Hansen, \& Kronberger, 2014); however, cultures with different backgrounds, such as Arabic culture, could be overlooked.

Arabic language takes the fifth place in world's most used languages and each day more people from Arabic cultures interact with interactive systems (Anbar, 2012). This means that it is crucial to think about Arabic cultures in the context of gamified applications. However, 
there is still a demand for identifying the elements that should be adapted and defining localisation criteria that guide the designers of Arabic gamified systems. Researchers in this domain should also focus on studying the effects of these adaptations on users' acceptability of Arabic systems and on users' behavioural changes (e.g., in their workplaces).

This paper addresses the cultural-specific elements that will compose gamified systems and would have effect on the users' acceptability of Arabic systems. We focus this research effort on the Arabic culture, identifying the specific user interface elements that will compose a gamified system as well as the factors that might intrinsically or extrinsically motivate Arab users to adjust their behaviours. For that, we designed a questionnaire based on visual elements and conducted individual interviews to expand our findings. Our contribution, therefore, is related to the understanding of localisation of cultural elements for Arabic societies as a hybrid design processes. We go beyond the cultural dimensions often utilised in cross-cultural studies and propose an inclusive systematic model through a combination of cultural and visual elements. We frame the research contributions of this paper as follows:

1. Defining criteria for localizing Arabic Gamified Systems that takes into consideration the cultural factors of the Arabic users as well as the factors that affect their engagement, motivation and behaviours.

2. Proposing a hybrid design model for localising Arabic gamified systems that is composed of personalized elements and localised and non-localised elements.

In the following sections, we first provide a background about gamification and the influence of cultural aspects in interactive systems. We, then, open the research for the application in the context of Arabic culture, reinforcing the perspectives for different types of rewards and the characteristics of the localised system. We conduct a questionnaire and interviews with experts, in order to identify the validity of our hypotheses. To conclude, we present a model for localisation of Arabic gamified systems, through a hybrid perspective.

\section{Related Work}

Because the customization of user interfaces to suit the requirements of users who belong to a specific culture is a multidimensional problem that requires taking many aspects into consideration (e.g., cultural factors and visual factors), this section briefly summarizes the research work related to the areas that have to be considered when localising software systems.

\subsection{Gamification}

By definition, gamification is a design process that involves play, fun and user experience (Werbach \& Hunter, 2012), particularly through the employment of game design features into non-game settings (Deterding et al., 2011), such as work environment, health and learning. However, it is possible to point out differences on the way people interact with gamified systems. For example, considering health applications, women might have more positive perceptions of the incentives received through the gamified system and social connections, if compared to men (Koivisto \& Hamari, 2014). This means that individuals' perspectives might vary and cultural values could be a strong variation to be studied. 
Considering cultural influences and gamification, (Khaled, 2015) have proposed six dynamics of relationships between people in gamified systems, such as competition, information sharing, normative activities, interdependence and sense of community, supported by rewards, points and achievements (Khaled, 2015). This means that the manipulation of the elements, together with the culturally-situated strategies could provide better interactions for users. However, little research has been conducted in the area of studying the cultural requirements of Arabic users that influence their engagement in gamified solutions, which opens this study for the analysis of cross-cultural design and HCI.

\subsection{Culture, Design and HCI}

Culture is a system of patterns that differentiates people of one group from the other $(\mathrm{G}$. Hofstede, 1991), incorporating traditions and shared meanings (Flores, Dufresne, \& Levesque, 2013). Individuals' perceptions might also have significant effect on their acceptance of Web-based systems. Barber and Badre (1998) have argued that culture and usability are affected by each other in designing web interfaces and they suggest merging them into one term, which they refer to as "culturability" (Barber \& Badre, 1998). They give an example of how the colours used for different elements of web interfaces (e.g., links, backgrounds and navigation bars) might lead to user satisfaction if these colours are consistent with the expectations of the target users. Kuljis J. et al. have also proposed a categorization of the elements that should be considered when localising a web interface design to a particular culture (Juric, Kim, \& Kuljis, 2003). According to their classification, a web interface element might be either a visual, audiovisual or verbal (Juric et al., 2003). Images, icons, symbols are all considered as visual properties of a web interface whereas currency, date formats, time formats and the language of the written text are verbal features. In this study, a criteria for localising Arabic gamified systems is proposed. This criteria takes into consideration all the visual and cultural preferences that might have a significant impact on the acceptability of these systems.

\subsection{Human-Computer Interaction}

In a web-based system, the translation of the language of the interface is not enough to provide a successful localisation of the application. In this case, it is important to consider other elements such as colours, the navigational structure, the layout and the perceptions of the targeted countries about the elements of the interface (Collins, 2002). For example, some ideas and images might not be acceptable in all cultures such as using images of women in a system that is used by Saudi Arabian people (Collins, 2002).

Previous studies involving cross-cultural issues in HCI usually consider the discussion about localization, internationalization and culturalization as guidelines and standards to be followed in the design of cross-cultural applications. Essentially, those concepts function basically in the same way, separating the cultural elements from the system and adapting them (Bourges-Waldegg, Paula, \& Scrivener, 1998). Considering this, prior research (Yeo, 1996) has classified localization elements for Cultural User Interface (CUI) into overt and covert factors. According to (Yeo, 1996) covert elements are related to intangible and specific factors, including graphics, colours, functionality, mental models and metaphors, and 
overt factors are tangible elements (e.g., dates, calendar, translation etc.). In the case of this paper, we look at localization from the perception of design elements involving intangible elements, especially regarding visual cues, and tangible elements that will be incorporated in the application, such as the left-to-right flow of the Arabic language. Consistently, existing literature in $\mathrm{HCI}$ in different cultures is usually related to representational variations among cultures, like colours, icons, symbols, pictures, time formats, jargon and abbreviations, where the difficulty in understanding them can impact learnability and user's preferences (BourgesWaldegg et al., 1998).

\subsection{User Interface Design}

Graphics, colour, typography, sound, animation, navigation, simplicity or complexity, choice structures and metaphors (Marcus \& Gould, 2000), contrast, uniformity and consistency compose the elements of user interface design (Garrett, 2010). In web applications, user interface design is usually situated around the surface and skeleton of the user experience design, followed by the structure (composed by interaction design and information architecture), scope and the main strategy (involving user needs and product objectives) (Garrett, 2010). Although this aspect is related to the web context, it could be applicable for other situations that include user experience design, such as software design.

However, considering the variations across cultures, (D. A. Norman, 2004) have already stated that the reflective level of emotional design, which is related to emotion, feelings and cognition, is the most susceptible to vary across cultures, experience, education and individual differences. This means that user interface design has a significant role in the design for different cultures. Especially in user interface design principles, user interface design can be analysed through the lenses of Hofstede dimensions (Marcus \& Gould, 2000), which could reflect the characteristics of a situated culture. This shows that the design of the interface is a reflection of the situated culture. For example, in cultures with high uncertainty avoidance, the user interface design should represent simplicity, clear metaphors, redundant colours and typography and in cultures with low uncertainty avoidance, the complexity of the elements should be extended to the choices and navigation of the system (Marcus \& Gould, 2000).

In addition, considering marketing and advertising in website design, symbolic and aesthetic aspects of the visual presentations (including background colours) are subjected to different cultures, influencing also the consumption of traditional and non-traditional media (Hermeking, 2005). Hofstede's dimensions of culture (G. Hofstede, 1991) have also supported this relationship and there was a correlation between the cultural dimensions proposed by Hofstede and the design of user interfaces.

\subsection{Metaphors}

The concept of metaphors is applicable to cross-cultural studies in HCI because they are related to analogies or familiarity (Carroll, Mack, \& Kellogg, 1987), which is consistent to the principle that before performing a task, users try to find connections in their mind and associative memory (Lang, 2007). Additionally, considering the perception of meaningful experiences, metaphors are usually used as a component to elicit emotions (Desmet \& 
Hekkert, 2007). In essence, metaphors can assist in the representation and description of people, objects, structures, processes, consequences and expression of values, through structural (parts of the system), operational (behaviour of the system) and pragmatic (understanding of the interface) metaphors (Marcus, 1998). For example, metaphors could be applied to improve communication into multi-cultural systems, through conceptual metaphors for interaction design (de Castro Salgado, de Souza, \& Leitao, 2009). Thus, those three expressions of metaphors could help to improve the system development.

Also, it is important to highlight that in cross-cultural studies, metaphors could be interpreted in different ways. For example, cultures from different backgrounds could perceive the icon/symbol for "thumb up" as some positive or as an insult (Plocher, Rau, \& Choong, 2012). This means that the consideration of metaphors in different cultures needs to be carefully thought of in the design process. Thus, considering the gamified system, metaphors could be employed through the interaction of the system and through user interface design, including the implementation of icons and symbols that are familiar for Arabic users. For this reason, we open the next section for the description of the gamified system according to the HCI propositions for cross-cultural studies.

\section{Design for Gamified Arabic Systems}

The localisation process of software systems to Arabic cultures overlooks many essential characteristics of the Arabic language (Abufardeh \& Magel, 2008). Designers of user interfaces for gamified project management software should understand the requirements for Middle Eastern cultures. Through investigating the literature and according to the localisation requirements related to cultural theories (see Table 1) and previous Arabisation attempts, we summarise the design considerations for the Arabic localisation of user interface elements in Table 2. In the context of gamified systems, this is not different. Thus, this leads to our research question: What are the culturally specific design elements for gamified systems in Arabic cultures?

Table 1: Hofstede's cultural dimensions for Arabic cultures ( Hofstede, 2001; Sears \& Jacko, 2007)

\begin{tabular}{|c|c|c|}
\hline Cultural Marker & Value & Rank \\
\hline Power distance index & 80 & 7 \\
\hline Individualism index & 38 & 26 \\
\hline Masculinity index & 53 & 23 \\
\hline Uncertainty avoidance index & 68 & 27 \\
\hline
\end{tabular}

In order to provide a set of patterns to understand thinking, feeling and mental models, Hofstede defined four dimensions (G. H. Hofstede, 2001). For example, Table 1 presents the values of the cultural markers identified by Hofstede that are representing some of the properties of the Arabic cultures (G. H. Hofstede, 2001). Interestingly, there is a difference between a click stream of a user belonging to an individualistic culture and a person from a collectivistic culture (Luna et al., 2002). Most Arabic cultures are collectivistic rather than 
individualistic and this fact can be exploited by recognizing team achievements in gamified systems. Further, the value of the uncertainty avoidance is relatively high and therefore Arabic interfaces are expected to be clear and understandable. In a gamified system, the rules for assigning points and badges should be clear to reduce the level of scepticism of the users. Furthermore, large number of links and references to external websites help in reducing the level of uncertainty in Arabic web systems (Marcus \& Hamoodi, 2009a). Considering this aspect, it is possible that the rewarding systems and the incentives provided by Arabic gamified systems could be different from Western-based systems. Therefore, it is possible to suggest that:

H1: Arabic users prefer different types of reward for their achievements

The value of the masculinity cultural marker helps interface designers in choosing the colours of their interfaces. For Arabic cultures, masculinity colours should be used for the majority of interface elements. Furthermore, having a high value of this cultural dimension implies that gender-distinction should be visible in the related interface as well as having clear roles and responsibilities for each user (Marcus \& Gould, 2000). It can be noticed that the value of the power distance index is very high which means that Arabic cultures have hierarchical organization of responsibilities and therefore the power in these cultures is distributed unequally (Marcus \& Gould, 2000). This implies that users of Arabic systems should be given different rights to access information and leaders should be distinguished in these online social groups. Furthermore, expert members should be granted higher authorities and the social roles of those members should be visible in the Arabic systems.

\subsection{User Interface Preferences}

One way to understand user interface preferences according to cultural backgrounds is through colour. Previous research has already argued that colour has an important influence in people's preferences, emotions and perceptions and should not be analysed without considering cultural aspects (Crozier, 1999). Essentially, colour carries meaning and signs when culturally situated (Kress \& Leeuwen, 2002). For this reason, cultural differences and similarities could be investigated considering the meaning that colours have in specific cultures. For example, red colour is linked to danger in America whereas Chinese people associate it with happiness (Barber \& Badre, 1998). Similarly, people in the United States relate the white colour with purity whereas white colour is related to death in Japan and China (Barber \& Badre, 1998). Furthermore, the meaning of green-coloured objects in Arabic cultures is associated with strength, generosity and fertility while green in linked to criminality in France.

Thus, the manipulation of colour in design has a strong impact into people's perceptions and attitudes. In the design of brands, for example, colour could influence the acceptance and recognition of products, encouraging intentions to purchase and, therefore, affecting consumer behaviour. Hence, colour could not only impact the process of decision-making but could also influence people's memory, as a fixed feature to be printed in the memory image (Crozier, 1999). Additionally, although colour is a significant example of cultural meaning, it could be also a representation for different genders. For example, previous study (Bonnardel, 
Beniwal, Dubey, Pande, \& Bimler, 2012) comparing British and Indian cultures has found that the differences among genders were more expressive for female and male respondents rather than just the cultural variation.

Based on the results of a study that investigated the colours used in Arabic websites, presented in (Khanum, Fatima, \& Chaurasia, 2012), the majority of them have used the white colour for backgrounds since it is a sign of purity in Middle Eastern cultures. Further, based on Hofstede's score for masculinity index, previous studies suggest eliminating colours that are linked to femininity and therefore the dominant colours in Arabic web interfaces should be grey, blue and green (Al-kwai, Alkhaybari, \& Al-muaythir, 2014; G. H. Hofstede, 2001; Khanum et al., 2012; Marcus \& Hamoodi, 2009b). Because Arabic users associate blue with protection, this colour is sometimes used for colouring hyperlinks and menus' backgrounds (Khanum et al., 2012). For images and logos, it is acceptable to have multiple colours while ensuring the masculinity colours are dominating (Al-kwai et al., 2014; Khanum et al., 2012; Marcus \& Hamoodi, 2009b). This means that colours might carry important values. Another way to convey cultural aspects in the interface design is through metaphors (i.e., related to familiar environments (Carroll et al., 1987)). Considering this perspective it is possible to assume that:

H2: Different design considerations affect the attitudes of Arab users in gamified systems

Cultural preferences can also influence the way users perceive the system usefulness and ease of use, which could impact users' satisfaction while interacting with a system (Evers \& Day, 1997). However, in a gamified system this could be related to motivational aspects. Motivation is one of the core principles of gamification (Nicholson, 2012). In cross-cultural studies, particularly in Eastern and Western cultures, the motivational process seemed to differ. For interdependent (collectivistic) cultures, social features would be more relevant and motivating. For independent (individualistic) cultures, aspects of agency and expression of internal needs would be more significant (Markus \& Kitayama, 1991). This means that some aspects of the gamified system might enhance motivational factors. Therefore, it is possible to suggest that:

H3: Arabic developers will feel more motivated while interacting with a culturally-specific interface designs.

Based on our conducted literature review, we present a localisation criteria that should be considered when Arabising gamified applications (see Table 2). We evaluate the applicability of following the design considerations that are shown in Table 2 and test our hypotheses in Sections 4, 5 and 6. 
Table 2: The design criteria proposed for localising all the interface elements in Arabic gamified systems

\begin{tabular}{|c|c|c|}
\hline Criteria & Element & Description \\
\hline \multirow{2}{*}{$\begin{array}{l}\text { Information } \\
\text { Content }\end{array}$} & Date & $\begin{array}{l}\text { Using Hijri calendars. } \\
\text { Using DD/MM/YYYY as the date format. }\end{array}$ \\
\hline & Time & $\begin{array}{l}\text { Using the 12-hours system and taking into consideration the working hours in most } \\
\text { Arabic institutions (8a.m. to 2p.m.). }\end{array}$ \\
\hline $\begin{array}{l}\text { Collating } \\
\text { Sequences }\end{array}$ & \multicolumn{2}{|c|}{ Using Arabic diacritics in the user interface when needed. } \\
\hline \multirow{2}{*}{ Language } & Spacing & $\begin{array}{l}\text { More spaces are required in the user interface elements that have Arabic texts because } \\
\text { Arabic words are longer that English words. }\end{array}$ \\
\hline & Translation & $\begin{array}{l}\text { There are no Arabic translations for all English words and therefore some English } \\
\text { terminologies could be used without translation. }\end{array}$ \\
\hline Images & \multicolumn{2}{|c|}{$\begin{array}{l}\text { - } \quad \text { Women images should only be used when needed. } \\
\text { - Text-based images are preferred because Middle Eastern cultures have high uncertainty avoidance } \\
\text { index. }\end{array}$} \\
\hline \multirow{3}{*}{ Page Layout } & Writing flow & Right-to-Left. \\
\hline & Menus & Positioned horizontally at the top side of the web pages. \\
\hline & Logos & Positioned at the top right side of the web pages. \\
\hline \multirow{4}{*}{ Colours } & White & $\begin{array}{l}\text { - } \quad \text { Background colour of the web pages } \\
\text { - } \quad \text { Font colour of menus. }\end{array}$ \\
\hline & Blue & $\begin{array}{l}\text { - } \quad \text { Background colour of menus. } \\
\text { - } \quad \text { Font colour of hyperlinks. }\end{array}$ \\
\hline & Green & $\begin{array}{l}\text { Used in many elements of the interface because it is considered as a holy colour in } \\
\text { Arabic cultures (Collins, 2002). }\end{array}$ \\
\hline & $\begin{array}{l}\text { Multi- } \\
\text { colouring }\end{array}$ & Logos and images. \\
\hline $\begin{array}{l}\text { Navigation } \\
\text { Structure }\end{array}$ & \multicolumn{2}{|c|}{$\begin{array}{l}\text { Because Arabic cultures have high uncertainty avoidance index, the pages should follow a hierarchical } \\
\text { structure to make it easier to find the required page. }\end{array}$} \\
\hline \multirow{2}{*}{ Font } & Type & Tahoma or Arial. \\
\hline & Size & $12 \mathrm{px}$ \\
\hline
\end{tabular}

\section{Methodology}

For the evaluation of our propositions, we have designed a methodology that includes questionnaires and interviews (see Figure 1). Questionnaires were utilized to collect data from individuals who worked in the software industry (e.g., designers, developers, testers and software analysts). After collecting and analysing the results of the questionnaires, we interviewed Arabic experts who have at least 5 years of experience working on software project management tools, designing Arabic user interfaces or conducting research on HCI related areas. Considering $\mathrm{H} 1, \mathrm{H} 2$ and $\mathrm{H} 3$, we have attempted to understand users' 
preferences through the application of a questionnaire. For that, we have designed a survey with representative images, following the implementations of mood boards. Mood boards could be used to identify and clarify affective content. For example, in a study with TV adverts, mood boards were utilised in order to identify the emotional qualities and subjective evaluation of communications (Chang, Diaz, Catala, Chen, \& Rauterberg, 2014).

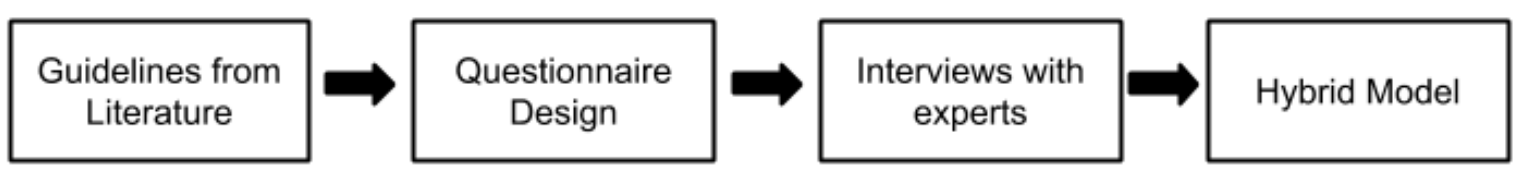

Figure 1: Research Methodology

According to McDonagh, Bruseberg and Haslam (2002), mood boards could function as a visual collection of images that are often selected from magazines or online websites. The selection of mood boards by users could be an effective tool to evaluate affective relationship between users and particular tasks. For example, McDonagh, Bruseberg and Haslam (2002) selected mood boards from a design team and presented to users with the aim to evaluate a specific task (e.g., ironing) (McDonagh, Bruseberg, \& Haslam, 2002). In addition, this technique was utilised to initiate the discussion of a focus group (McDonagh et al., 2002).

In the case of our study, we have gathered quantitative data from the mood boards in order to draw a specific guideline for user interface localisation for gamified systems in Arabic cultures. In addition, the idea of collecting data from colours and visual effects in the system are consistent to McDonagh, Bruseberg and Haslam (2002) approach to visually evaluate products (McDonagh et al., 2002). Consistently, the adaptation of interface design according to cultural preferences could influence beliefs and perceptions about the usefulness and ease of use of interface design (Evers \& Day, 1997) .

From the questionnaires, in order to outline and expand the findings, we have conducted interviews with seven Arabic users of software management tools, HCI experts and software designers. After the interviews, we have drawn a hybrid design model with the results from both interviews and questionnaires.

\subsection{Questionnaire Design}

One of the reasons of conducting this questionnaire includes understanding the preferences that are related to the presentation of information in Arabic gamified systems. The importance of this evaluation is to decrease the level of boredom and disengagement caused by design errors in the layout of the user interface elements. Although the main motivation behind gamifying software solutions is to increase the motivation levels and productivity of the users, these mistakes might negatively affect the user experience and therefore play a major role in having unsatisfied users.

For the purpose of understanding the cultural preferences of Arab software developers and customizing the visual elements and functionality of gamified systems accordingly, we conducted a mood board-based questionnaire that collected information about our 
participants' preferred choices related to many areas including rewards, colours and culturally specific considerations. For the questionnaire, we have selected images and statements to collect data about users' emotional attachment and preferences according to visual elements of gamified systems. The questionnaire was designed following the perspectives of visual elements or mood boards. Based on the localisation criteria presented in Table 2, we selected a set of mood board images. The majority of these images were specifically designed for the purpose of this study (e.g., the ones related to the Arabic localisation of user interface elements) whereas some images were taken from the Internet. This is because we found that they can be used for evaluating users' perceptions and emotional responses in some specific scenarios that they might encounter in their workplace. The images are available in (Alomar, Wanick, \& Wills, 2015).

The questionnaire consisted of three main parts. In the first part of the questionnaire, we asked about our users' educational backgrounds, ages and genders. The second part of the questionnaire included questions about the visual elements of the user interface that were specifically designed for understanding our participants' most preferred user interface properties. In the third part of the survey, we prepared some scenarios and evaluated our users' reactions towards some situations that might be encountered while they are developing or managing the development of software systems. Table 8 (in Appendix A) describes the questions that were included in the conducted questionnaire.

Before distributing our questionnaire and interviewing our participants, their consent was taken and they were informed that no personally identifiable information will be collected. 63 Arab software developers participated in the survey ${ }^{1}$ that was designed specifically for this study and around $95 \%$ of them were from 20 to 30 years old. Only $20 \%$ of them were male developers. Furthermore, half of them rated their computer-related background as knowledgeable whereas more than $40 \%$ of them are experts. 63 is a suitable sample size for this study as when tested for G*Power (Faul, Erdfelder, Buchner, \& Lang, 2009), with $\alpha=$ .05 and $\beta=0.95$, the effect size was 0.419 , which is considered between medium and large (Cohen, 1992).

\subsection{Interviews}

For the interviews, we recruited Arabic experts who have experienced software management tools in their work for at least 5 years. Our aim is to identify the elements highlighted by the mood boards and discuss with them some issues regarding achievements in groups, group participation at work, cultural-related incentives and rewards. The approach chosen is expert review. According to (Nielsen \& Landauer, 1993), three to five evaluators is enough to understand issues in interface design. In order to saturate the results, we have selected seven Arabic participants. The respondents were interviewed for the purpose of extracting reasonable justifications of the results that we obtained in our questionnaire. All of them are software engineers who had worked in development teams in the Saudi software market. Further, four of them are interface designers and the majority of them are HCI experts.

\footnotetext{
${ }^{1}$ ERGO number 17946
} 
In our interviews, we asked our participants many questions that are related to designing the visual elements of Arabic gamified systems as well as the factors that affect their productivity and increase their level of collaboration in software development teams. The results obtained in our questionnaire were also presented to our participants and discussed with them. We asked our participants about their thoughts about work collaboration and whether they would feel more motivated if they could have more collaborative work. We also collected their feedback regarding the factors that could enhance the level of collaboration between members of development teams. Our questions also addressed the design elements of Arabic gamified systems. We asked our participants about the properties of the user interface design that might increase the engagement of the users. In our interview sessions, we also went over all the obtained results of our mood board-based evaluation and discussed them with the interviewed seven software engineers, software designers and HCI experts. We linked our observations to Hofstede's cultural dimensions for Arabic cultures and used the thematic analysis approach to analyse the collected data (Braun, Virginia and Clarke, 2006). The following sections summarise the findings of questionnaires and the seven conducted interviews.

\section{Results, findings and analysis}

In this section, we analyse the responses collected through our conducted mood boards-based questionnaire and verify our results by linking them with the findings of our interviews. The main aim behind conducting the questionnaire was to test our hypotheses $(\mathrm{H} 1, \mathrm{H} 2$, and $\mathrm{H} 3$ ) and evaluate the applicability of the localisation criteria that we defined. We have done a frequency analysis of the responses and checked for correlations between expertise, gender and user interface choice.

When the participants of our questionnaire were asked about their feelings while playing online games, 59\% of them indicated that they feel happy. This suggests that the developers' attitudes towards game-like activities, such as gamification, are positive. Similar findings were found when they were asked about their mood whilst coding, 35 respondents stated that they feel happy and they like their work. However, software engineers who follow agile methods face challenges related to the dynamicity in the requirements and having to quickly respond to the market needs. When we asked the participants about their mood when the requirements of their system change, $81 \%$ of them indicated that they feel sad or frustrated. Similarly, $79 \%$ of them stated that they feel frustrated or angry when they try to correct the programming errors that emerge when they code. Therefore, it is important to study the factors that could contribute to increasing the engagement of software engineers and therefore lead to enhancing their productivity levels.

\subsection{H1: Achievements and Rewards}

Although Hofstede's theory of cultural dimensions states that Arab societies are collectivist rather than individualist, more than $60 \%$ of the respondents preferred to have money as a reward for their achievements. Because the survey presented having vacations and being with their families as possible rewards that they might have, the results show that Arab software developers value extrinsic rewards over intrinsic ones. However, as the participants had 
different levels of expertise, we explored this preference in the experience level (see Figure 2).

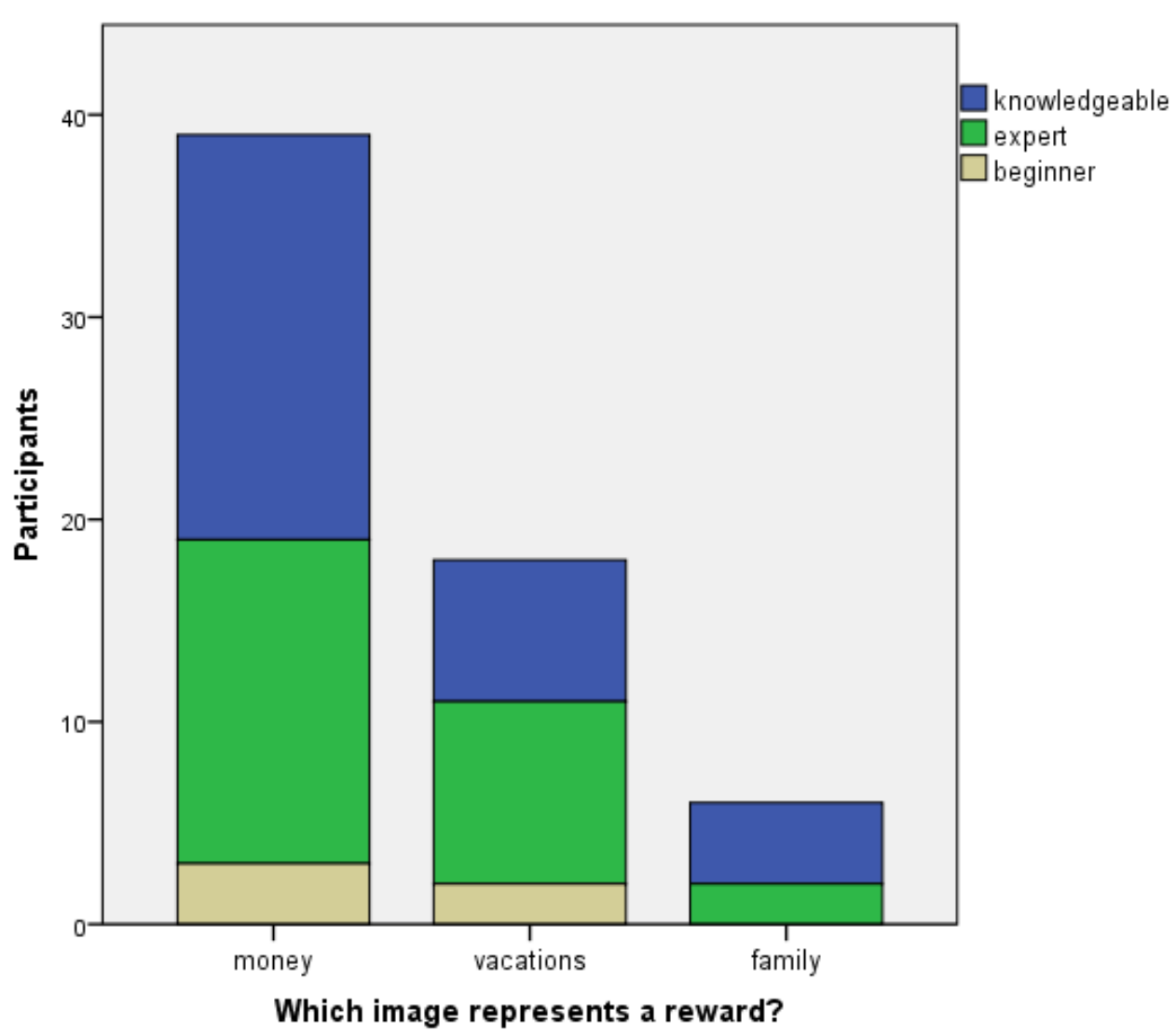

Figure 2 :The relationship between computer background and preferred rewards

Considering the choices about rewards and interface elements, beginners preferred money or vacation, excluding family from rewards. For knowledgeable users, money was the most preferable reward. We also observed that, for knowledgeable users, the non-localised badge collection (NLB) is the preferred one, if compared to the localised badge collection (LB). This aspect was a constant characteristic in the three levels of expertise. The interesting fact is that the majority of beginners that preferred vacations as rewards also preferred the LB. However, this is an isolated characteristic. When tested for Pearson Correlation (G. Norman, 2010), there is no statistically significant correlation between expertise and badge selection.

Furthermore, when they were asked about what represents group achievements, $56 \%$ of the respondents chose the image that implies that they consider collaboration as a reward and they care for the welfare of the whole social group. Furthermore, choosing an image that takes into consideration winning as a group and sharing their feelings with their team members by more than $40 \%$ of the respondents implies that Arab developing teams value group achievements and give them more attention. One of the interviewed participants explained:

"We often find ourselves motivated to do our best if we work with excited and experienced team members." (P2) 
Therefore, our findings show that Arabic software engineers would prefer seeing groups and a more collectivistic visualisation, rather than the metaphor for palm trees. Thus, our findings support Hofstede's value of the individualism cultural dimension for Middle Eastern cultures.

When tested for correlations, it is possible to find a statistically significant relationship between their mood while coding and the reward choice ( $r=0.287$ ) (see Table 3). Group achievements had also a relationship between their mood while coding $(r=0.442)$. The responses of the participants were borderline in terms of mood while coding: $56 \%$ felt happy and $41 \%$ felt in a situation that is almost impossible to solve. This suggests that working together might be the most effective way to solve problems while coding. The reward choice, in this case monetary, could be a reflection of this borderline situation. The results suggest that this impossibility to solve problems while coding could reflect in the choice for monetary rewards.

Computer-related background had a statistically significant and positive relationship with mood when customer makes changes in the requirements $(r=0.296)$. This suggests that if users have more experience, they might be keener to make changes in their work. There is a negative and statistically significant relationship between mood correcting errors and achievements $(\mathrm{r}=-0.377)$. This indicates that representation of achievements might not have a positive impact in mood improvement. Furthermore, there is a negative correlation between leaderboards choice and mood while coding errors $(\mathrm{r}=-0.272)$. Thus, it is possible that gamified elements for improving motivation to correct errors might not work or should be better designed for productivity enhancement.

Table 3: Simple correlation coefficients (r) among the elements of the questionnaire that showed statistically significant results.

\begin{tabular}{|l|l|l|l|l|l|l|l|}
\hline & $\mathbf{1}$ & $\mathbf{2}$ & $\mathbf{3}$ & $\mathbf{4}$ & $\mathbf{5}$ & $\mathbf{6}$ & $\mathbf{7}$ \\
\hline 1. Leaderboard & 1 & & & & & & \\
\hline 2.Achievement & .058 & 1 & & & & & \\
\hline 3. Group achievement & -.083 & -.029 & 1 & & & \\
\hline $\begin{array}{l}\text { 4. Computer-related background } \\
\text { 5. Reward }\end{array}$ & .098 & -.014 & .241 & 1 & & & \\
\hline $\begin{array}{l}\text { 6. Mood whilst coding } \\
\text { 7. Mood when your customer makes }\end{array}$ & -.149 & .181 & -.098 & -.023 & 1 & & \\
\hline
\end{tabular}

$\mathrm{N}=63 *$. Correlation is statistically significant at the 0.05 level (2-tailed) **. Correlation is statistically significant at the 0.01 level (2-tailed). 


\subsection{H2: Design and Presentation of Game Elements}

Nine questions focused on understanding the factors that might help software designers in choosing the properties of the game elements that are placed in Arabic gamified software solutions (see Table 8 in Appendix A). Although more than $80 \%$ of the participants were females, the colours that were preferred by the majority of them were masculine colours (see Table 9 in Appendix B). 59\% of the respondents preferred green coloured rewards and around $25 \%$ of them chose blue as the most appropriate colour for presenting rewards. This also confirms Hofstede's value of the masculinity index for Arabic cultures because the masculine colours were chosen by more than $70 \%$ of the respondents. Although the majority of the respondents were female, there is a small difference in the choices for yellow (as shown in Table 4). However, this could induce further investigation. When tested for Pearson Correlation (r) in order to measure associations, it was not possible to find a statistically significant correlation between gender and colour preference in this case. This could suggest that the actual preferences could be cultural and not gender-specific. Therefore, using masculine colours by the designers of game design elements might increase the level of engagement and motivation of their target Arab users.

Table 4: Gender differences and colour preferences

\begin{tabular}{llllll}
\hline \begin{tabular}{l} 
Which colours illustrate the way you feel when you receive \\
a reward? \\
\hline Gender
\end{tabular} Blue & Green & Orange & White & Yellow \\
\hline Male & $21.79 \%$ & $\mathbf{6 2 . 8 2 \%}$ & $6.41 \%$ & $7.69 \%$ & $1.28 \%$ \\
Female & $31.58 \%$ & $\mathbf{4 7 . 3 7 \%}$ & $0 \%$ & $10.53 \%$ & $\mathbf{1 0 . 5 3 \%}$ \\
\hline
\end{tabular}

In our interviews, we asked our participants about the colours that can be used to represent rewards in gamified systems and the results confirm Hofstede's finding that masculine colours are preferred in the Arabic cultures. All our participants agreed that green, blue and white are the best for representing rewards. They justified their opinions by stating that they link green-coloured objects to success, rewards and victory. Some mentioned that receiving blue-coloured rewards motivates them to work hard and achieve better results. Further, they indicated that their acceptance of software systems is highly affected by the colours used in the user interfaces of these systems.

We extracted the badge design preferences by asking many questions that examined the applicability of adding visual elements in the badges as well as text and numbers. For localising the badges for the Arabic user, we discussed the results of the seventh, eighth and ninth questions with the interviewed HCI experts and software designers (see Table 8 and Table 9). We observed that our participants preferred the designs that minimise the cognitive overhead required to understand the meanings of these badges. This also confirms the value of the uncertainty avoidance index assigned to Arabic cultures in Hofstede's theory of cultural dimensions. For example, the majority of our respondents preferred the badges that 
included the number of points that will be awarded if they unlock these badges. For localising the badges, our respondents preferred the first option of the eighth question because its frame reflects the cultural values of Arabic cultures and it looks better than the third option. Our seven HCI experts stated the frame of the third option is not suitable for the context of the system and the purpose of rewarding the badge (see Table 5). Further, many participants emphasized on the importance of including a mix of text, icons and numbers in the badges to increase the understanding and learnability of gamified systems. One of the interviewed designers stated that Arabic people prefer to be presented in hierarchies and this fact can be considered while designing Arabic badges. She mentioned:

"Particularly for Arab individuals, they should be differentiated based on their achievements. For example, whenever I earn more points or unlock more badges, the corresponding gamified system should make my achievements visible to my teammates and clearly show my position with respect to all other members in my work environment." (P4)

She suggested incorporating visual elements that differentiate and rank the members of a given social group according to their achievements. Other interviewees also emphasized on the importance of designing gamified systems in a simple, clear and understandable way. Furthermore, some software engineers suggested sponsoring some badges by well-known companies in the software industry (e.g., Oracle and IBM) and indicated that this will significantly impact their productivity levels. The ranking and the sponsoring strategies could be also related to Hofstede dimension of power distance, which reinforces our proposition that the badges should be localised.

Table 5: The eighth question in our questionnaire: which badge is more appropriate?

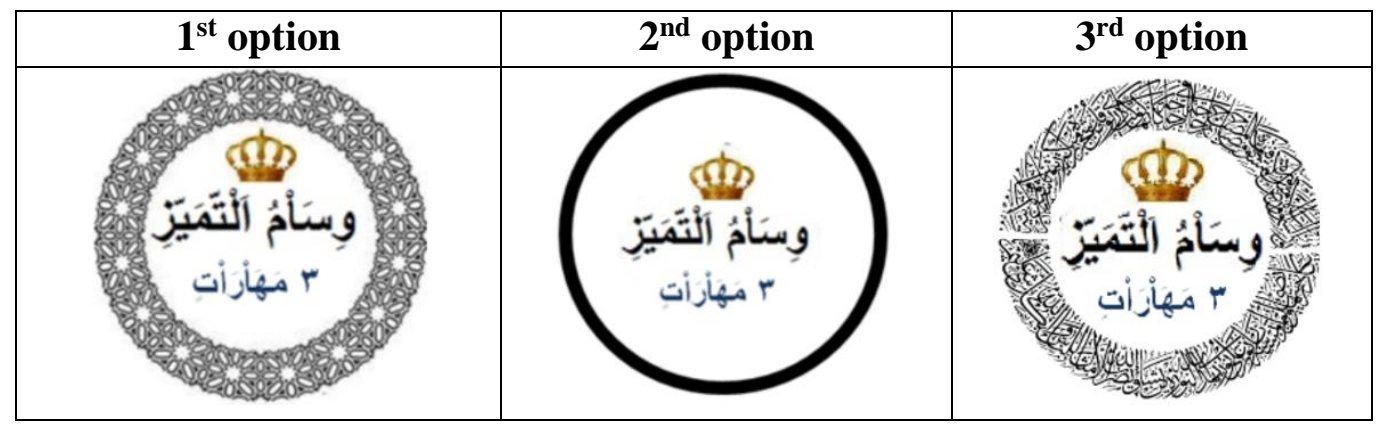

The participants also preferred using culturally specific elements (e.g., drawn from Islamic art) for framing the badges. This implies that the visual presentation of game elements might significantly affects users' motivation to play or use the corresponding gamified system. However, software designers have also to take the culturally specific factors of their target cultures into consideration while designing user interfaces of gamified software systems. For designing Arabic leaderboards, the leaderboards presented in the questionnaire differ in that some of them included avatars whereas other had images of real people (see Figure 3). 


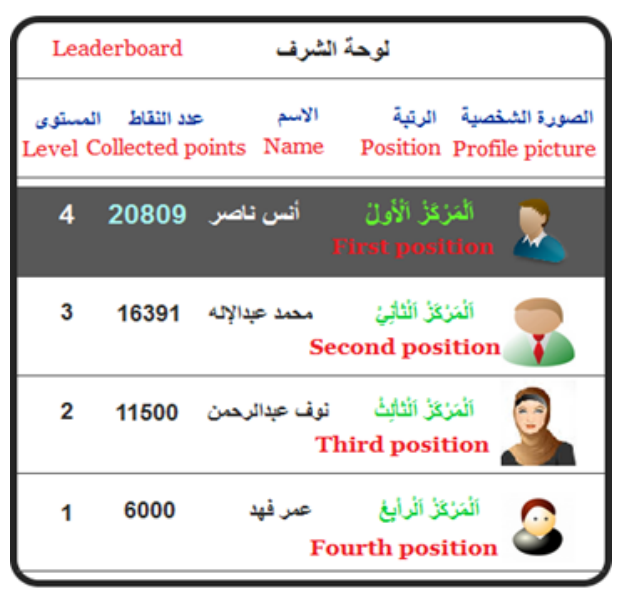

Figure 3: An example of localised leaderboard

The questionnaire also evaluated whether the Arabic user prefer to be presented on a leaderboard as the holder of the first position or using other naming systems (e.g., the best team member and the hard-working developer). The results of the questionnaire show that around 57\% preferred presenting their real images in the leaderboards rather than using avatars and ranking them in a sequential order based on their achievements (e.g., number of earned points and their unlocked levels). This can be linked to the high value of the uncertainty avoidance index in Hofstede's theory of cultural dimensions, which implies that the Arabic user prefers to have clear and abstract representations of information that can be understood with a minimum mental overhead. The results also show that adopting a ranking system that takes the expertise of the developers into consideration is the most preferable system because around 79\% preferred the beginner, professional and expert badges over the other ranking schemes (see Table 9). Therefore, as software designers, we should add user interface elements and customize the functionality of gamified systems to distinguish the members in Arabic social groups according to their achievements. Because the value of the power distance index for Arab cultures is particularly high, this implies that Arab individuals will be motivated to use a particular system if they know that their achievements will be recognized in their work environments. Therefore, organizing them into hierarchies in their social groups accordingly would be more motivating.

In addition, it is possible to see that the computer background also provided differences in the preferences of the gamified system. For beginners, the indication of "beginners" in the nomination of ranking or the use of numbers could make more sense than the "boss-princeking" (see Table 6). On the other hand, for knowledgeable users, the non-localised badges are more important. This could show one small variation of expertise and preferences. It is possible that the familiarity of knowledgeable users with the systems that are not localised is related to familiarity with software systems in general. 
Table 6: The relationship between computer background and preferences for representations

\begin{tabular}{|c|c|c|c|c|c|c|}
\hline \multirow[b]{3}{*}{$\begin{array}{l}\text { Computer } \\
\text { Background }\end{array}$} & \multicolumn{6}{|c|}{ Which image represents higher ranks? } \\
\hline & \multicolumn{2}{|c|}{$\begin{array}{c}\text { Beginner-professional- } \\
\text { expert }\end{array}$} & \multicolumn{2}{|c|}{ Boss-prince-king } & \multicolumn{2}{|c|}{ Numbers } \\
\hline & $L B$ & $N L B$ & $L B$ & $N L B$ & $L B$ & $N L B$ \\
\hline Beginner & $22.22 \%$ & $11.11 \%$ & - & - & - & $22.22 \%$ \\
\hline Expert & $14.63 \%$ & $19.51 \%$ & - & $9.76 \%$ & $4.88 \%$ & $7.32 \%$ \\
\hline Knowledgeable & $19.15 \%$ & $34.04 \%$ & $2.13 \%$ & $2.13 \%$ & - & $12.77 \%$ \\
\hline
\end{tabular}

In this study, we tried to know the most suitable way for presenting the levels in a gamified Arabic system. The respondents were presented with three different ways for representing the levels, which are stars, text-based descriptions and trees. From the perspective of localisation, we expected that users would choose the trees ranking system or the system with written text (Alomar et al., 2015). However, in the questionnaires, the answers show that $63 \%$ preferred representing the levels as stars (see Table 9). Our interviewed experts explained this design preference by indicating that stars were preferred for presenting the levels because they can be understood easily without significant cognitive overheads. This also suggests that visualizing the game elements and presenting suitable metaphors might positively affect the user experience of the user. However, this does not mean that these visualizations are enough but they have to be complemented by text-based achievement summaries to increase the level of understanding and therefore decreasing the level of uncertainty in the meaning implied by different elements presented in user interfaces of Arabic gamified systems. Our HCI experts also mentioned that using the stars can simply conveys the meaning just by looking at the length of the line that contain the stars and without reading the written text.

For presenting the winners in leaderboards, some of our experts indicated that Arab people has privacy concerns related to presenting their photos and they recommended using avatars in gamified systems although most of our questionnaire respondents preferred presenting real images in leaderboards. Others supported this idea by mentioning that they experience problems related to having some persons who refuse to add their photos in the software project management systems used in their work environments. Further, they preferred mentioning clearly who is the first, second and third winners in leaderboards rather than writing "the best member" and "the professional employee". Consistent with the ranking information from the badges, the visualisation of the three best workers could show the cultural preference for hierarchical elements.

\subsection{H3: Cultural-Specific Elements}

We conducted the questionnaire to gather information about the preferences of the Arabic user and especially about the factors that are specifically related to the Arabic culture. For this reason, the respondents were asked about the most preferable option for presenting the 
time and date in an Arabic gamified system. As shown in the results presented in Table 9, the results confirm what the literature has presented in that more than half of the respondents preferred to present the time in the twelve-hour system and as a written text. Similarly, for presenting the dates, the Hijri calendar was preferred by around 59\% of the respondents. However, we expected these percentages to be higher and therefore we discussed these issues with our interviewed experts. Some of our experts indicated that using visual elements to present times (e.g., a watch metaphor) is adopted internationally and can be understood easily. However, for Arabic user interfaces, our experts recommended adopting the 12-hour system and using a combination of text-based descriptions and icons. On the other hand, all the interviewed experts agreed that Gregorian calendars are widely adopted in the industry because they are fixed as opposed to Hijri dates that change depending on the moon. However, because Arab countries take Hijri calendars into consideration for deciding vacation days, all our interviewed experts recommended considering both calendars in Arabic gamified systems and presenting them in a simple and clear way. This could reflect the idea that some elements could be personalised, giving the user a choice for customisation. The participants also preferred to have diacritics used all over the system to make user interface elements more understandable for them.

Other design considerations that were recommended by the interviewed experts include designing Arabic logos that demonstrate the purpose of the system easily. Further, ensuring that the Arabic translation is accurate and reflects the intended meaning. They also emphasized on the importance of considering the Right-to-Left orientation for presenting the Arabic content, which reinforces the concept that main elements such as language need to be localised.

Table 9 in Appendix B shows the descriptions of visual elements gathered from the questionnaire. The mood board images can be found in (Alomar et al., 2015). It is possible that from the user interface aspect, the green could be a way to highlight important elements for the users and using stars represent high levels could have positive effects on user engagement. On the other hand, our results show that the most preferred ranking system is localised. This means that it could have identification with the badges.

\section{A Hybrid Cultural Design Model}

The characteristics presented in our analysis showed a combination of elements that should be considered when situating gamified systems in Arabic cultures. A selection of specific elements were categorised into localised, non-localised and personalised elements (as shown in Figure 4 and Table 7). As a result, it is possible to draw a concept that combines all three characteristics, as a hybrid model. In this scenario, we select the particular patterns driven by the preferences found in the results of our interviews and questionnaires. For example, in the localised elements, we found that language, avatar and badge design should be localised. By that, we expect that the design process should consider "native" and familiar elements before the design of the gamified system. 


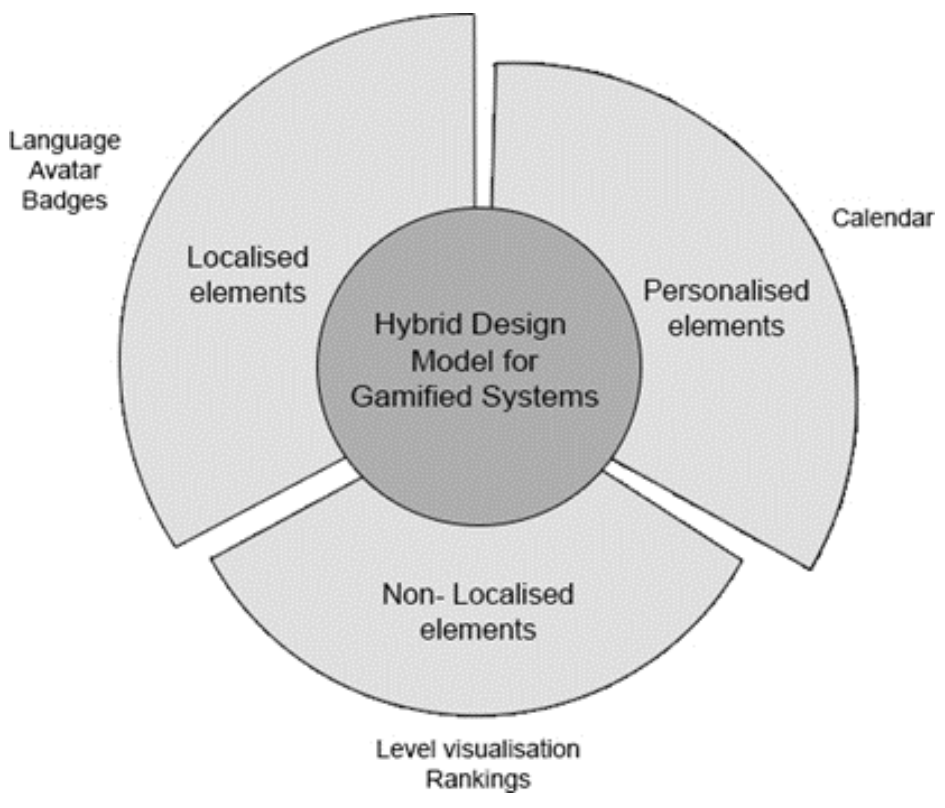

Figure 4: Hybrid Design Model

The non-localised elements were the result from the preferences related to the visualisation of levels in gamified systems. Going against our hypothesis (H3), respondents preferred "stars" to visualise their level, rather than trees (as metaphor) or texts. The same happened with the visualisation of rankings. For this reason, we separate level and rankings as elements that could follow a Westernised model of representation.

The personalised elements presented in the gamified interface show that the choice of calendar is important for users. This is strongly related to their context of use and expansion of options, particularly enhanced by the use of both calendars. However, this aspect was not found in the other gamified elements.

Table 7: Localised, non-localised and personalised elements

\begin{tabular}{|l|l|l|}
\hline Localised elements & Non-localised/common elements & Personalised elements \\
\hline 1. Arabic Language. & 1. Level visualisation (stars). & $\begin{array}{l}\text { 1. Calendar choice (Gregorian } \\
\text { and Hijri). }\end{array}$ \\
\hline 2. Avatar representation (no photos). & $\begin{array}{l}\text { 2. Ranking visualisation (Beginner, } \\
\text { professional and expert). }\end{array}$ & - \\
\hline 3. Arabic-related Badges. & - & - \\
\hline
\end{tabular}

\section{Limitations}

The limitations of this work are related to the field of application of the gamified system in Arabic cultures. Although we have interviewed experts and gathered preferences from users of gamified systems, such as gamified software management tools, it is possible that Arabic users from other contexts could have different perspectives of gamification. However, the 
Hybrid Model shows that before thinking about localisation and management tools with gamification, it is necessary to think which components should be localised, non-localised and personalised.

The current work focuses only on Arabic cultures. However, the structure of this research could be applied in other cultural scenarios, in order to build a comparison and a bigger perspective of gamification and culture. Our sample focused on studying the preferences of Arabic users who have software engineering related background as well as the factors that affect their motivation in their workplaces. Therefore, our findings might not be generalizable to other user groups (e.g., people who do not have technical background or did not work in software development teams). However, this will not affect the validity of our findings because our design guidelines can be used for localising all Arabic systems and our research methodology can be followed for studying how to localise software systems to other cultural groups.

\section{Conclusion and discussion}

The incorporation of game elements into non-game software solutions and the creative expansion of user interface designs increase the complexity of localising software systems to a particular cultural group. To avoid cultural conflicts and increase the acceptability of software solutions, software designers have to take into consideration the visual elements of user interfaces, the functionality provided by their systems and the cultural perceptions and values of their target user groups. The designers of gamified solutions have also to consider the factor that maximize or minimize the engagement and motivation of their users. In this paper, a comprehensive investigation and evaluation of cultural considerations as well as the preferences of the Arabic user are provided. We started by proposing design guidelines for localising Arabic gamified systems. This was followed by conducting questionnaires and interviews for the purpose of understanding the best ways for presenting visual user interface elements, rewarding users in Arabic gamified systems and customizing the functionality of these systems to suit the requirements of the Arabic users.

After surveying 63 participants and interviewing 7 experts, our findings show that Arabic users preferred to be extrinsically rewarded for their achievements. Considering the perspectives related to collectivist cultures, we expected that Arabic users would prefer more collective types of rewards for their achievements, like being with family (H1). However, we have found that Arabic software developers prefer monetary rewards. Reasons for that could be related to the knowledge background, work experience and issues associated with solving coding problems. On the other hand, this paper showed that different design considerations affect the attitudes of Arabic users in systems that employ gamification and software development $(\mathrm{H} 2)$.

From the results we have found that not all elements of the gamified system for software engineers should be localised (H3). In this scenario, there is a combination of localised items (following previous research such as Hofstede dimensions), non-localised items (e.g., stars) and personalisation (e.g., the choice for both calendars). This could mean that localised systems that utilise gamification in the work environment should take into account three 
elements: the localised elements, non-localised elements and personalisation. Consistently, the concept of personalisation is related to control and could enhance the user autonomy while interacting with the system. However, what we propose is a mixture or a blend of those three systems. Our results can be utilized for localising all Arabic software systems and our methodology can be repeated for studying the cultural requirements of other cultural groups. We also expect that the proposed hybrid model can be useful in the design of an adaptive, custom and personalised Arabic gamified system, following Arab culture design preferences and requirements.

Another element mentioned that could be explored is the sense of security which could be strongly related to the uncertainty avoidance dimension of Hofstede. However, in the digital world, it is possible that this element could be expanded. In Hofstede, security is related to the fear of an unknown feature. In the digital environment, this could be related to data privacy. For this reason, this element could be explored in future work

\section{Appendix A}

Table 8: The questions included in our mood board-based questionnaire as well as descriptions about the images that were provided as choices. The images are available in (Alomar et al., 2015)

\begin{tabular}{|c|c|c|c|c|c|c|c|}
\hline \# & Question & Purpose & $1^{\text {st }}$ image & $2^{\text {nd }}$ image & $3^{\text {rd }}$ image & $4^{\text {th }}$ image & $\begin{array}{l}5^{\text {th }} \\
\text { image }\end{array}$ \\
\hline 1 & $\begin{array}{l}\text { Which image } \\
\text { represents a } \\
\text { reward? }\end{array}$ & $\begin{array}{l}\text { Understanding } \\
\text { the preferred } \\
\text { types of } \\
\text { reward. }\end{array}$ & $\begin{array}{l}\text { Monetary } \\
\text { rewards. }\end{array}$ & Holidays & $\begin{array}{l}\text { Being with } \\
\text { family }\end{array}$ & - & - \\
\hline 2 & $\begin{array}{l}\text { Which images } \\
\text { represent time? }\end{array}$ & $\begin{array}{l}\text { Understanding } \\
\text { the best way } \\
\text { for presenting } \\
\text { time. }\end{array}$ & $\begin{array}{l}\text { 24-hour system, } \\
\text { text-based, no } \\
\text { symbols. }\end{array}$ & $\begin{array}{l}\text { 12-hour } \\
\text { system, text- } \\
\text { based, no } \\
\text { symbols. }\end{array}$ & $\begin{array}{l}\text { A clock } \\
\text { representing } \\
\text { 12-hour system } \\
\text { in a visual } \\
\text { form. }\end{array}$ & $\begin{array}{l}\text { A clock } \\
\text { representing } \\
\text { 24-hour } \\
\text { system in a } \\
\text { visual form. }\end{array}$ & - \\
\hline 3 & $\begin{array}{l}\text { Which image } \\
\text { represents group } \\
\text { achievements? }\end{array}$ & $\begin{array}{l}\text { Understanding } \\
\text { the social } \\
\text { meaning } \\
\text { behind group } \\
\text { achievements }\end{array}$ & $\begin{array}{l}\text { An image } \\
\text { representing a } \\
\text { group of happy } \\
\text { friends. }\end{array}$ & $\begin{array}{l}\text { An image } \\
\text { representing } \\
\text { collaboration }\end{array}$ & $\begin{array}{l}\text { An image } \\
\text { containing } \\
\text { palm trees to } \\
\text { test whether } \\
\text { Arabic users } \\
\text { associate } \\
\text { metaphors with } \\
\text { social } \\
\text { meanings. }\end{array}$ & - & - \\
\hline 4 & $\begin{array}{l}\text { Which colours } \\
\text { illustrate the way } \\
\text { you feel when you } \\
\text { receive a reward? }\end{array}$ & $\begin{array}{l}\text { Knowing the } \\
\text { best colours } \\
\text { for presenting } \\
\text { rewards. }\end{array}$ & Blue & Green & Orange & White & Yellow \\
\hline 5 & $\begin{array}{l}\text { Which image } \\
\text { represents date? }\end{array}$ & $\begin{array}{l}\text { Understanding } \\
\text { the preferred } \\
\text { calendar. }\end{array}$ & Hijri calendar & $\begin{array}{l}\text { Gregorian } \\
\text { calendar }\end{array}$ & - & - & - \\
\hline 6 & $\begin{array}{l}\text { Which image } \\
\text { represents higher } \\
\text { levels in the } \\
\text { gamified system? }\end{array}$ & $\begin{array}{l}\text { Understanding } \\
\text { the best way } \\
\text { for presenting } \\
\text { levels in a } \\
\text { gamified }\end{array}$ & $\begin{array}{l}\text { Text-based } \\
\text { representation } \\
\text { that includes } \\
\text { Arabic } \\
\text { numbers, }\end{array}$ & $\begin{array}{l}\text { Stars (5 stars, } \\
4 \text { stars, etc.) }\end{array}$ & $\begin{array}{l}\text { Trees with } \\
\text { different sizes } \\
\text { and numbers } \\
\text { supported by } \\
\text { text-based }\end{array}$ & - & - \\
\hline
\end{tabular}




\begin{tabular}{|c|c|c|c|c|c|c|c|}
\hline & & system. & $\begin{array}{l}\text { Arabic text and } \\
\text { diacritics. }\end{array}$ & & descriptions. & & \\
\hline 7 & $\begin{array}{l}\text { Which image } \\
\text { represents } \\
\text { achievement? }\end{array}$ & $\begin{array}{l}\text { Understanding } \\
\text { the preferred } \\
\text { option for } \\
\text { visualizing } \\
\text { achievements } \\
\text { in gamified } \\
\text { systems. }\end{array}$ & $\begin{array}{l}\text { Badges } \\
\text { containing } \\
\text { Arabic text, } \\
\text { stars, Arabic } \\
\text { diacritics and } \\
\text { cultural-specific } \\
\text { frames. }\end{array}$ & $\begin{array}{l}\text { Badges } \\
\text { containing } \\
\text { numbers, } \\
\text { cups and } \\
\text { stars. }\end{array}$ & - & - & \\
\hline 8 & $\begin{array}{l}\text { Which badge is } \\
\text { more appropriate? }\end{array}$ & $\begin{array}{l}\text { Exploring the } \\
\text { best option for } \\
\text { framing } \\
\text { badges. }\end{array}$ & $\begin{array}{l}\text { A badge with } \\
\text { an Islamic } \\
\text { frame (visual } \\
\text { elements drawn } \\
\text { from the } \\
\text { Islamic art). }\end{array}$ & $\begin{array}{l}\text { A badge } \\
\text { without a } \\
\text { frame. }\end{array}$ & $\begin{array}{l}\text { A badge with } \\
\text { an Islamic } \\
\text { frame (text } \\
\text { elements drawn } \\
\text { from the Arabic } \\
\text { culture). }\end{array}$ & - & \\
\hline 9 & $\begin{array}{l}\text { Which image } \\
\text { represents higher } \\
\text { ranks? }\end{array}$ & $\begin{array}{l}\text { Understanding } \\
\text { the preferred } \\
\text { ways for } \\
\text { ranking users } \\
\text { in gamified } \\
\text { systems. }\end{array}$ & $\begin{array}{l}\text { Three badges } \\
\text { following this } \\
\text { ranking } \\
\text { scheme: expert, } \\
\text { professional } \\
\text { and beginner. }\end{array}$ & $\begin{array}{l}\text { Three badges } \\
\text { following this } \\
\text { ranking } \\
\text { scheme: king, } \\
\text { prince and } \\
\text { boss. }\end{array}$ & $\begin{array}{l}\text { Three badges } \\
\text { following this } \\
\text { ranking } \\
\text { scheme: } 3,2 \\
\text { and } 1 .\end{array}$ & - & . \\
\hline 10 & $\begin{array}{l}\text { Which image } \\
\text { represents your } \\
\text { mood whilst } \\
\text { playing online } \\
\text { games? }\end{array}$ & $\begin{array}{l}\text { Understanding } \\
\text { whether our } \\
\text { users are } \\
\text { interested in } \\
\text { online games. }\end{array}$ & $\begin{array}{l}\text { An image } \\
\text { representing } \\
\text { excited gamers. }\end{array}$ & $\begin{array}{l}\text { An image } \\
\text { representing } \\
\text { bored gamers. }\end{array}$ & $\begin{array}{l}\text { An image } \\
\text { representing } \\
\text { enthusiastic } \\
\text { gamers. }\end{array}$ & - & 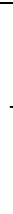 \\
\hline 11 & $\begin{array}{l}\text { Which image } \\
\text { represents your } \\
\text { mood whilst } \\
\text { coding? }\end{array}$ & $\begin{array}{l}\text { Understanding } \\
\text { whether our } \\
\text { participants } \\
\text { love their } \\
\text { work. }\end{array}$ & $\begin{array}{l}\text { An image } \\
\text { representing a } \\
\text { bored } \\
\text { programmer. }\end{array}$ & $\begin{array}{l}\text { An image } \\
\text { representing a } \\
\text { happy } \\
\text { programmer. }\end{array}$ & $\begin{array}{l}\text { An image } \\
\text { representing a } \\
\text { sad } \\
\text { programmer. }\end{array}$ & - & \\
\hline 12 & $\begin{array}{l}\text { Which image } \\
\text { represents your } \\
\text { mood whilst } \\
\text { correcting your } \\
\text { programming } \\
\text { errors? }\end{array}$ & $\begin{array}{l}\text { Understanding } \\
\text { our } \\
\text { participants' } \\
\text { feelings when } \\
\text { they } \\
\text { experience } \\
\text { problems in } \\
\text { their } \\
\text { workplaces. }\end{array}$ & $\begin{array}{l}\text { An image } \\
\text { representing an } \\
\text { angry software } \\
\text { engineer. }\end{array}$ & $\begin{array}{l}\text { An image } \\
\text { representing a } \\
\text { happy } \\
\text { software } \\
\text { engineer. }\end{array}$ & $\begin{array}{l}\text { An image } \\
\text { representing a } \\
\text { frustrated } \\
\text { software } \\
\text { engineer. }\end{array}$ & - & \\
\hline 13 & $\begin{array}{l}\text { Which image } \\
\text { represents your } \\
\text { mood when your } \\
\text { customer make } \\
\text { changes in the } \\
\text { requirements of } \\
\text { the system that you } \\
\text { are developing? }\end{array}$ & $\begin{array}{l}\text { Understanding } \\
\text { whether our } \\
\text { participants' } \\
\text { motivation is } \\
\text { negatively } \\
\text { affected when } \\
\text { experiencing } \\
\text { problems in } \\
\text { their } \\
\text { workplaces. }\end{array}$ & $\begin{array}{l}\text { A happy } \\
\text { person. }\end{array}$ & A sad person. & $\begin{array}{l}\text { A frustrated } \\
\text { person. }\end{array}$ & - & \\
\hline 14 & $\begin{array}{l}\text { Which leaderboard } \\
\text { is more appealing } \\
\text { to you? }\end{array}$ & $\begin{array}{l}\text { Understanding } \\
\text { the most } \\
\text { preferred way } \\
\text { for presenting } \\
\text { leaderboards. }\end{array}$ & $\begin{array}{l}\text { Leaderboard } \\
\text { that follows the } \\
\text { ranking } \\
\text { scheme: 1st } \\
\text { position, } 2 \text { nd }\end{array}$ & $\begin{array}{l}\text { Leaderboard } \\
\text { that follows } \\
\text { the ranking } \\
\text { scheme: } 1 \mathrm{st} \\
\text { position, } 2 \mathrm{nd}\end{array}$ & $\begin{array}{l}\text { Leaderboard } \\
\text { that follows the } \\
\text { ranking } \\
\text { scheme: the } \\
\text { best member, }\end{array}$ & $\begin{array}{l}\text { Leaderboard } \\
\text { that follows } \\
\text { the ranking } \\
\text { scheme: the } \\
\text { best }\end{array}$ & . \\
\hline
\end{tabular}




\begin{tabular}{|l|l|l|l|l|l|l|}
\hline & & $\begin{array}{l}\text { position, etc. } \\
\text { The leaderboard } \\
\text { presents the } \\
\text { winners with } \\
\text { real images. }\end{array}$ & $\begin{array}{l}\text { position, etc. } \\
\text { The } \\
\text { leaderboard } \\
\text { presents the } \\
\text { winners with } \\
\text { avatars. }\end{array}$ & $\begin{array}{l}\text { the professional } \\
\text { member, etc. } \\
\text { The } \\
\text { leaderboard } \\
\text { presents the } \\
\text { winners with } \\
\text { avatars. }\end{array}$ & $\begin{array}{l}\text { member, the } \\
\text { professional } \\
\text { member, } \\
\text { etc. } \\
\text { The } \\
\text { leaderboard } \\
\text { presents the } \\
\text { winners } \\
\text { with real } \\
\text { images. }\end{array}$ \\
\hline 15 & $\begin{array}{l}\text { Which one is more } \\
\text { appropriate for } \\
\text { summarizing your } \\
\text { achievements in a } \\
\text { gamified system? }\end{array}$ & $\begin{array}{l}\text { Understanding } \\
\text { the most } \\
\text { preferred way } \\
\text { for presenting } \\
\text { achievements } \\
\text { summaries. }\end{array}$ & $\begin{array}{l}\text { Visual } \\
\text { representations } \\
\text { of badges, } \\
\text { leaderboards } \\
\text { and collected } \\
\text { number of } \\
\text { points. }\end{array}$ & $\begin{array}{l}\text { Text-based } \\
\text { description } \\
\text { summarizing } \\
\text { users } \\
\text { achievements. }\end{array}$ & - & - \\
\end{tabular}

\section{Appendix B}

Table 9: Descriptions of the visual elements chosen by most of our participants (based on the results of the questionnaire and the descriptions provided in Table 8)

\begin{tabular}{|c|c|c|}
\hline Question & Answer & Percentage \\
\hline $\begin{array}{l}\text { Part 1: } \\
\text { How do you rate your computer-related background? }\end{array}$ & Knowledgeable & $49 \%$ \\
\hline What is your age group? & $25-30$ & $60 \%$ \\
\hline What is your gender? & Female & $83 \%$ \\
\hline $\begin{array}{l}\text { Part 2: } \\
\text { Which image represents a reward? }\end{array}$ & 1st image & $60 \%$ \\
\hline Which image represents time? & 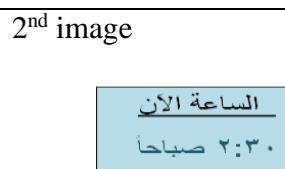 & $52 \%$ \\
\hline Which image represents group achievements? & $2^{\text {nd }}$ image & $56 \%$ \\
\hline $\begin{array}{l}\text { Which colours illustrate the way you feel when you receive } \\
\text { a reward? }\end{array}$ & $2^{\text {nd }}$ image & $59 \%$ \\
\hline
\end{tabular}




\begin{tabular}{|c|c|c|}
\hline Which image represents date? & 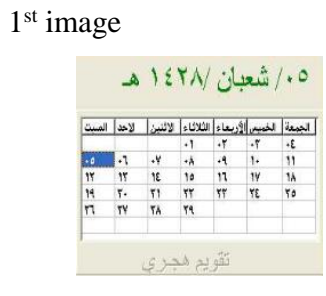 & $59 \%$ \\
\hline Which image represents higher levels in a gamified system? & $\begin{array}{r}2^{\text {nd }} \text { image } \\
\star \star \star \star \star \\
\star \star \star \star \\
\star \star \star\end{array}$ & $63 \%$ \\
\hline Which image represents achievement? & $2^{\text {nd }}$ image & $68 \%$ \\
\hline Which badge is more appropriate? & $1^{\text {st }}$ image & $52 \%$ \\
\hline Which image represents higher ranks? & $1^{\text {st }}$ image & $79 \%$ \\
\hline $\begin{array}{l}\text { Which image represents your mood whilst playing online } \\
\text { games? }\end{array}$ & & $59 \%$ \\
\hline Which image represents your mood whilst coding? & $2^{\text {nd }}$ image & $56 \%$ \\
\hline $\begin{array}{l}\text { Which image represents your mood whilst correcting your } \\
\text { programming errors? }\end{array}$ & $3^{\text {rd }}$ image & $57 \%$ \\
\hline
\end{tabular}




\begin{tabular}{|c|c|c|}
\hline $\begin{array}{l}\text { Which image represents your mood when your customer } \\
\text { make changes in the requirements of the system that you are } \\
\text { developing? }\end{array}$ & $2^{\text {nd }}$ image & $46 \%$ \\
\hline Which leaderboard is more appealing to you? &  & $57 \%$ \\
\hline $\begin{array}{l}\text { Which one is more appropriate for summarizing your } \\
\text { achievements in a gamified system? }\end{array}$ &  & $52 \%$ \\
\hline
\end{tabular}

\section{References}

Abufardeh, S., \& Magel, K. (2008). Software Localization: The Challenging Aspects of Arabic to the Localization Process (Arabization). In Proceedings of the IASTED International Conference on Software Engineering (pp. 275-279).

Al-kwai, L., Alkhaybari, A., \& Al-muaythir, A. (2014). Gamification in Arabic Interactive Educational Applications : Cultural and Language Considerations in Motivational Affordance of Design Elements. In INTED2014 Proceedings (pp. 4545-4556).

Alomar, N., Wanick, V., \& Wills, G. B. (2015). The moodboard-based questionnaire used in this paper. Retrieved October 06, 2015, from https://nouraalomar.typeform.com/to/nUOG8Z

Anbar, T. (2012). An NLP Based Fully Distributed Arabic Search Engine, 2(2), 6-11. 
Barber, W., \& Badre, A. (1998). Culturability: The Merging of Culture and Usability. In Proceedings of the 4th Conference on Human Factors and the Web (pp. 1-10).

Retrieved from http://research.microsoft.com/en-us/um/people/marycz/hfweb98/barber/

Bonnardel, V., Beniwal, S., Dubey, N., Pande, M., \& Bimler, D. (2012). Color preferences: a British/Indian comparative study. In Colour and Environment: AIC2012 Conference Proceedings (pp. 306-309).

Bourges-Waldegg, Paula, \& Scrivener, S. A. (1998). Meaning, the central issue in crosscultural HCI design. Interacting with Computers, Oxford University Press, 9(3), 287309.

Braun, Virginia and Clarke, V. (2006). Using thematic analysis in psychology. Qualitative Research in Psychology, 3(2), 77-101.

Carroll, J. M., Mack, R. L., \& Kellogg, W. A. (1987). Interface metaphors and user interface design. IBM Thomas J. Watson Research Division.

Chang, H.-M., Diaz, M., Catala, A., Chen, W., \& Rauterberg, M. (2014). Mood boards as a universal tool for investigating emotional experience. Design, User Experience, and Usability. User Experience Design Practice, 220-231.

Cohen, J. (1992). Quantitative methods in psychology. Psychological Bulletin, 112(1), 155159.

Collins, R. W. (2002). Software Localization for Internet Software : Issues and Methods. Software, IEEE, 19(2), 74-80.

Crozier, W. R. (1999). The meanings of colour: Preferences among hues. Pigment $\backslash \&$ Resin Technology, 28(1), 6-14.

De Castro Salgado, L. C., de Souza, C. S., \& Leitao, C. F. (2009). Conceptual metaphors for designing multi-cultural applications. In Web Congress, 2009. LA-WEB'09. Latin American.

Desmet, P., \& Hekkert, P. (2007). Framework of product experience.National Science Council, Taipei. International Journal of Design, 1(1).

Deterding, S., Sicart, M., Nacke, L., O’Hara, K., \& Dixon, D. (2011). Gamification. using game-design elements in non-gaming contexts. In CHI'11 Extended Abstracts on Human Factors in Computing Systems (pp. 2425-2428).

Evers, V., \& Day, D. (1997). The role of culture in interface acceptance. In Human-Computer Interaction INTERACT'97 (pp. 260-267).

Faul, F., Erdfelder, E., Buchner, A., \& Lang, A.-G. (2009). Statistical power analyses using G* Power 3.1: Tests for correlation and regression analyses. Behavior Research Methods, 41(1), 1149-1160. 
Flores, M. T. da S. B., Dufresne, A., \& Levesque, G. (2013). Cultural semiotics in design elearning. In Proceedings of World Congress on Communication and Arts (pp. 23-29).

Garrett, J. J. (2010). Elements of user experience, the: user-centered design for the web and beyond. Pearson Education.

Hermeking, M. (2005). Culture and internet consumption: contributions from cross-cultural marketing and advertising research. Journal of Computer-Mediated Communication, $11(1), 192-216$.

Hofstede, G. (1991). HOFSTEDE : Cultures And Organizations - Software of the Mind (pp. 1-29). USA, New York: McGraw-Hill.

Hofstede, G. H. (2001). Culture's consequences: Comparing values, behaviors, institutions, and organizations across nations.

Juric, R., Kim, I., \& Kuljis, J. (2003). Cross Cultural Web Design: An Experiences of Developing UK and Korean Cultural Markers. In Information Technology Interfaces, 2003. ITI 2003. Proceedings of the 25th International Conference on (pp. 309-313).

Khaled, R. (2015). GAMIFICATION AND CULTURE 11. The Gameful World: Approaches, Issues, Applications. MIT Press, 301-320.

Khanum, M. A., Fatima, S., \& Chaurasia, M. A. (2012). Arabic Interface Analysis Based on Cultural Markers. International Journal of Computer Science Issues, 9(1), 255-262.

Khaslavsky, J. (1998). Integrating culture into interface design. In CHI 98 Cconference Summary on Human Factors in Computing Systems (pp. 365-366).

Koivisto, J., \& Hamari, J. (2014). Demographic differences in perceived benefits from gamification. Computers in Human Behavior, 35, 179-188.

Kress, G., \& Leeuwen, V. (2002). Colour as a semiotic mode: notes for a grammar of colour. Visual Communication 1.3, 343-368.

Lang, A. (2007). The limited capacity model of mediated message processing. Theorizing Communication, Readings across Traditions.

Luna, D., Peracchio, L. a., \& de Juan, M. D. (2002). Cross-Cultural and Cognitive Aspects of Web Site Navigation. Journal of the Academy of Marketing Science, 30(4), 397-410. doi:10.1177/009207002236913

Marcus, A. (1998). Metaphor design for user interfaces. In CHI 98 Cconference Summary on Human Factors in Computing Systems (pp. 129-130).

Marcus, A., \& Gould, E. W. (2000). Crosscurrents: cultural dimensions and global Web userinterface design. Interactions, 7(4), 32-46.

Marcus, A., \& Hamoodi, S. (2009a). Culture's Impact on Arabic Website Design. In HCI International Conference, by Springer Verlag (pp. 1-9). 
Marcus, A., \& Hamoodi, S. (2009b). The Impact of Culture on the Design of Arabic Websites. Internationalization, Design and Global Development, 386-394.

Markus, H. R., \& Kitayama, S. (1991). Culture and the self: Implications for cognition, emotion, and motivation. American Psychological Association. Psychological Review, 98(2), 224.

McDonagh, D., Bruseberg, A., \& Haslam, C. (2002). Visual product evaluation: exploring users' emotional relationships with products. Applied Ergonomics, 33(3), 231-240.

Nicholson, S. (2012). A User-Centered Theoretical Framework for Meaningful Gamification A Brief Introduction to Gamification Organismic Integration Theory Situational Relevance and Situated Motivational Affordance. Games+Learning + Society, 8(1).

Nielsen, J., \& Landauer, T. K. (1993). A Mathematical Model of the Finding of Usability Problems. In Proceedings of the INTERACT'93 and CHI'93 conference on Human factors in computing systems. (pp. 206-213).

Norman, D. A. (2004). Emotional design: Why we love (or hate) everyday things.Basic books.

Norman, G. (2010). Likert scales, levels of measurement and the "laws" of statistics. Advances in Health Sciences Education: Theory and Practice, 15(5), 625-32. doi:10.1007/s10459-010-9222-y

Plocher, T., Rau, P.-L. P., \& Choong, Y.-Y. (2012). Cross-cultural design. Handbook of Human Factors and Ergonomics, 162-191.

Schrape, N. (2014). Gamification and Governmentality. Mathias Fuchs, Sonia Fizek, Paolo Ruffino, and Niklas Scharpe. L $\{$ "u\}neburg: Meson Press.

Sears, A., \& Jacko, J. (2007). The Human-Computer Interaction Handbook: Fundamentals, Evolving Technologies and Emerging Applications (Second Edi.).

UNESCO. (2013). Cultural Diversity | Education | United Nations Educational, Scientific and Cultural Organization. Retrieved from http://www.unesco.org/new/en/education/themes/leading-the-internationalagenda/education-for-sustainable-development/cultural-diversity/

Wagner, W., Hansen, K., \& Kronberger, N. (2014). Quantitative and Qualitative Research across Cultures and Languages: Cultural Metrics and their Application. Integrative Psychological and Behavioral Science, 48(4), 418-434.

Werbach, K., \& Hunter, D. (2012). For the Win: How Game Thinking Can Revolutionize Your Business (p. 144). Wharton Digital Press.

Yeo, A. (1996). Cultural user interfaces: a silver lining in cultural diversity. ACM SIGCHI Bulletin, 28(3), 4-7. 
Zichermann, G., \& Cunningham, C. (2011). Gamification by Design. (M. Treseler, Ed.) (First Edit.). O’Reilly Media, Inc. 